\section{Chloroquine as alternative antimalarial in systemic lupus erythematosus: response to '2019 update of the EULAR recommendations for the management of SLE: don't forget chloroquine' by Figueroa-Parra et al}

We thank Drs Figueroa-Parra et al for their interest in our paper $^{1}$ and their comment regarding the value of chloroquine (CQ) as an alternative antimalarial in systemic lupus erythematosus (SLE) ${ }^{2}$ As the authors point out, there are data, mostly for older studies, to support the efficacy of CQ in SLE. ${ }^{3}$ Nevertheless, over the last 20 years, hydroxychloroquine (HCQ) has largely displaced CQ in the USA and in Europe, mainly due to concerns for potential higher retinal toxicity of the latter (although no studies have formally tested different CQ doses in relation to toxicity). ${ }^{4}$ Accordingly, the vast majority of recent literature on the multiple benefits of antimalarial therapy refers to the use of HCQ, ${ }^{5}$ and there is general agreement that the latter should be the antimalarial of choice in SLE. Based on the above, the updated European League against Rheumatism recommendations for the management of lupus provide guidance reflecting current practice in the majority of settings and regions around the world. This being said, we acknowledge that in countries with significant cost differences between the two drugs, CQ may be considered as a justified alternative, ${ }^{6}$ with diligent monitoring for toxic retinopathy according to the recommendations.

\footnotetext{
Antonis Fanouriakis, ${ }^{\oplus 1}$ George K Bertsias, ${ }^{\circledR 2,3}$ Dimitrios T Boumpas ${ }^{1,4,5}$

${ }^{1}$ Rheumatology and Clinical Immunology Unit, 4th Department of Internal Medicine, "Attikon" University Hospital, Athens, Greece

${ }^{2}$ Department of Rheumatology, Clinical Immunology and Allergy, University Hospital of Heraklion, Heraklion, Greece

${ }^{3}$ Institute of Molecular Biology and Biotechnology, Foundation of Research and Technology-Hellas, Heraklion, Greece

${ }^{4}$ Laboratory of Autoimmunity and Inflammation, Biomedical Research Foundation of the Academy of Athens, Athens, Greece

${ }^{5}$ Joint Academic Rheumatology Program, Medical School, National and Kapodestrian University of Athens, Athens, Greece
}

Correspondence to Dr Antonis Fanouriakis, Rheumatology and Clinical Immunology Unit, 4th Department of Internal Medicine, "Attikon" University Hospital, Athens, 12462, Greece; afanour@med.uoa.gr

Handling editor Josef S Smolen

Competing interests None declared.

Patient consent for publication Not required.

Provenance and peer review Commissioned; internally peer reviewed.

(c) Author(s) (or their employer(s)) 2019. No commercial re-use. See rights and permissions. Published by BMJ.

\section{Check for updates}

To cite Fanouriakis A, Bertsias GK, Boumpas DT. Ann Rheum Dis Epub ahead of print: [please include Day Month Year]. doi:10.1136/annrheumdis-2019-215746

Received 23 May 2019

Accepted 24 May 2019

\section{Linked}

http://dx.doi.org/10.1136/annrheumdis-2019-215716

Ann Rheum Dis 2019;0:1. doi:10.1136/annrheumdis-2019-215746

\section{REFERENCES}

1 Fanouriakis A, Kostopoulou M, Alunno A, et al. 2019 update of the EULAR recommendations for the management of systemic lupus erythematosus. Ann Rheum Dis 2019:78:736-45.

2 Figueroa-Parra G, Gamboa-Alonso CM, De-Leon-Ibarra AL, et al. 2019 update of the EULAR recommendations for the management of SLE: don't forget chloroquine. Ann Rheum Dis 2019. doi:10.1136/annrheumdis-2019-215716. [Epub ahead of print: 24 May 2019].

3 Avina-Zubieta JA, Galindo-Rodriguez G, Newman S, et al. Long term effectiveness of antimalarial drugs in rheumatic diseases. Annals of the Rheumatic Diseases 1998:57:582-7.

4 Costedoat-Chalumeau N, Dunogué B, Leroux G, et al. A critical review of the effects of hydroxychloroquine and chloroquine on the eye. Clin Rev Allergy Immunol 2015;49:317-26.

5 Ruiz-Irastorza G, Ramos-Casals M, Brito-Zeron P, et al. Clinical efficacy and side effects of antimalarials in systemic lupus erythematosus: a systematic review. Ann Rheum Dis 2010;69:20-8.

6 Pons-Estel BA, Bonfa E, Soriano ER, et al. First Latin American clinical practice guidelines for the treatment of systemic lupus erythematosus: Latin American Group for the Study of Lupus (GLADEL, Grupo Latino Americano de Estudio del Lupus)Pan-American League of Associations of Rheumatology (PANLAR). Ann Rheum Dis 2018:77:1549-57. 